\title{
Effects of Milling Parameters on Distribution of Residual Stress During the Milling of Curved Thin-Walled Parts
}

\author{
Xiangjing Kong ${ }^{\mathrm{a}}$, Zishan Ding ${ }^{\mathrm{a}}$, Lijun $\mathrm{Xu}^{\mathrm{b}}$, Lijian Zhu ${ }^{\mathrm{b}}$, Jian Zhang ${ }^{\mathrm{b}}$, Chongjun $\mathrm{Wu}^{\mathrm{c}}$ and Alexander Isaev ${ }^{\mathrm{d}}$ \\ ${ }^{\mathrm{a}}$ College of Mechanical Engineering, University of Shanghai for Science \& Technology, CN-200093, Shanghai, China \\ bShanghai Space Propulsion Technology Research Institute, CN-201109, Shanghai, China \\ ${ }^{c}$ College of Mechanical Engineering, Donghua University, CN-201620, Shanghai, China \\ dMoscow State Technological University "STANKIN", Department of Cutting Tools and Forming Technologies, RU-127055, Moscow, \\ Russia
}

\begin{abstract}
With the increasing application of curved thin-walled parts, the evaluation and control of curved surface residual stress in milling are becoming increasingly demanding. However, effects of milling parameters on distribution of residual stress remains a major challenge in the present aerospace research areas. In this paper, , impacts of milling parameters on curved surface residual stress have been investigated in a series of residual stress experiments and simulations. It is found that the residual stress can be lowered by increasing milling speed and tool radius within a reasonable range. The superposition of curved surface residual stress under two machining conditions have been analyzed using the milling simulation model. It has been found that the curved surface residual stress induced by the subsequent cutting will be superimposed on the curved surface residual stress induced by the previous cutting and that the superposition rates of residual stress induced by up milling are larger than down milling.
\end{abstract}

\section{Introduction}

With the rapid development of advanced manufacturing, the demand of curved thin-walled parts is steadily increasing. Undesirable residual tensile stress generated by milling shortens the fatigue life of parts. Thus, it is important to research on impacts of milling parameters on distribution of residual stress induced by the milling of curved thin-walled parts.

Nowadays many scientific workers have performed a large number of thorough studies of optimization methods of aluminum milling parameters. For example, Fan et al. [1] proposed that the residual stress increases with the decreasing rounded cutting edge. Segawa et al. [2] designed a new tool geometry that can generate compressive residual stress on the machined surface. Experiments of Nasr et al. [3] show that the rounded corner of the blade would increase the residual tensile stress of the workpiece surface. Jiang et al. [4] found that with the increase of cutter diameter, residual stress and deformation can be reduced and material removal rate can be improved.

In terms of process parameters in plane milling, Fuh and $\mathrm{Wu}$ [5] proposed a numerical model to predict the residual stress of 2014-T6 alloy during milling. It is found that among the various machining parameters, the feed rate has the greatest influence on the residual stress. Arunachalam et al. [6] recommended the use of low cutting speed $(150 \mathrm{~m} / \mathrm{min})$ and small cutting depth $(0.05$ $\mathrm{mm}$ ), which could help obtain compressive residual stress or minimum tensile residual stress. Li et al. [7] believed that a smaller residual tensile stress would be generated at a higher feed speed. Garcia Navas et al. [8] pointed out that the tensile residual stress of AISI 4340 steel can be reduced under the condition of smaller feed and higher cutting speed. Li et al. [9] found that the use of larger cutting depth during rough machining and the use of varying cutting depths in different stages of finishing could reduce and optimize the deformation and residual stress effectively. Robinson et al. [10] studied the mechanism of residual stress redistribution after heat treatment of al 7449, and also discussed the influence of residual stress redistribution on the deformation of parts through the method of material removal layer by layer. Zeng et al. [11] studied the distribution law of residual stress in the micro-end milling process under a variety of cutting conditions by building a prediction model which could simulate the variation process of residual stress. Yang et al. [12] investigated the coupled distribution of initial and machining-induced residual stress, and found that the initial residual stress was superimposed on the machining-induced residual stress in the elastic deformation zone.

In terms of surface residual stress, Guo and Barkey [13] revealed that the coupling of process parameters to the cutting force and temperature affected the residual

e-mail: jiangxh@usst.edu.cn 
stress and deformation on curved surface. Mohammadpour et al. [14] found that the cutting speed and feed had important effects on the residual stress of the surface and subsurface after orthogonal cutting. Dong et al. [15] proposed a hybrid technique combining finite element method and statistical model. It is found that the surface residual stress changes from compression to tensile by increasing the cutting speed and feeding speed. Coto et al. [16]'s specific research on the effects of feeding and cutting speeds on the tensile residual stress demonstrated that the tensile residual stress increased with the accelerating feeding, while decreased with the accelerating cutting within a certain range. Masoudi et al. [17] found that the cutting force and temperature had direct effects on the curved surface residual stress and deformation of thin-walled parts. Singh and Agrawal [18] conducted an experimental study on the residual stress of the surface in deformation processing, and found that the residual stress of the surface significantly changed with the change of machining and forming parameters. Moreover, the curved residual stresses changed drastically with the machining and forming parameters. Nespor et al. [19] compared the residual stress state after processing ti-6al-4v with composite ball head milling method and orthogonal cutting method, and the results showed that only when the shape of workpiece and the subsurface deformation shape determined by tool motion were considered, the residual stress would be transferred to the subsurface. Jiang et al. [20] proposed a mathematical model between the curved surface maximum tensile residual stress and the Undeformed Chip Volume (UCV) (fz, R, ap and ae) of the ball end milling cutter. This mathematical model can quantify the influences of machining parameters on maximum tensile residual stress during the milling of Al2024 parts.

The above finding can be considered as a supplementary evidence on the effects of milling parameters on residual stress, but few of them is involved with the effects of milling parameters on distribution of residual stress during the milling of Al7050 curved thin-walled parts. Based on the analysis and comparison above, the more concerned in this paper is the effects of milling parameters on curved surface residual stress and its superposition.

\section{Theoretical models}

In this section, the material model of the simulation and the elastic stress model of the cutting process have been discussed.

\subsection{Material model}

Johnson-Cook cutting constitutive equation. The cutting software of AdvantEdge uses the model of oblique cutting to predict the stress and thermal. Moreover, the cutting constitutive equation, i.e. Johnson-Cook [21], could be written in the stress-strain relationship as Eq. (1):

$$
\sigma=\left(A+B \varepsilon^{n}\right) \cdot(1+c \cdot \ln \varepsilon) \cdot\left(1-\left(\frac{T-T_{\text {room }}}{T-T_{\text {melt }}}\right)^{m}\right)
$$

where $\sigma$ is stress, $\varepsilon$ is strain, $\mathrm{T}$ is deformation temperature, Troom is room temperature $\left(20^{\circ} \mathrm{C}\right)$, Tmelt is material melting temperature, $\mathrm{A}$ is material yield stress, $\mathrm{B}$ is strain hardening constant, $\mathrm{C}, \mathrm{n}, \mathrm{m}$ are coefficients of the material properties, all of them are usually obtained from the material tests or experiments. The coefficients of AL7050 are shown in Table 1.

Table1. The coefficient of J-C constitutive equation

\begin{tabular}{|c|c|c|c|c|c|}
\hline Material & $\begin{array}{c}\text { A } \\
(\mathrm{MPa})\end{array}$ & $\begin{array}{c}\text { B } \\
(\mathrm{MPa})\end{array}$ & $\mathrm{c}$ & $\mathrm{n}$ & $\mathrm{m}$ \\
\hline Al7050 & 402 & 328.6 & 0.007 & 0.26 & 1.3 \\
\hline
\end{tabular}

Material constitutive equations. The Power Law [22] is chosen as the material fracture damage constitutive equation as Eq. (2).

$$
\sigma\left(\varepsilon^{p}, \dot{\varepsilon}, T\right)=g\left(\varepsilon^{p}\right) \cdot \Gamma(\dot{\varepsilon}) \cdot \Theta(T)
$$

Where $g\left(\varepsilon^{p}\right)$ is strain hardening, $\Gamma(\varepsilon)$ is strain rate sensitivity, and ${ }^{\Theta(T)}$ is thermal softening. While the strain hardening function ${ }^{g\left(\varepsilon^{p}\right)}$ Eq. (3) and (4) for the power law are defined as:

$$
\begin{aligned}
& g\left(\varepsilon^{p}\right)=\sigma_{0}\left(1+\frac{\varepsilon^{p}}{\varepsilon_{0}^{p}}\right)^{\frac{1}{n}}, \text { if } \varepsilon^{p}<\varepsilon_{c u t}{ }^{p} \\
& g\left(\varepsilon^{p}\right)=\sigma_{0}\left(1+\frac{\varepsilon_{c u t}^{p}}{\varepsilon_{0}^{p}}\right)^{\frac{1}{n}}, \text { if } \varepsilon^{p} \geq \varepsilon_{c u t}{ }^{p}
\end{aligned}
$$

Where $\sigma_{0}$ is the initial yield stress, $\varepsilon^{p}$ is the plastic strain, ${ }^{\varepsilon_{0}^{p}}$ is the reference plastic strain, ${ }^{{ }_{\text {cut }}{ }^{p}}$ is the cut off strain, and $\mathrm{n}$ is the strain hardening exponent. And the thermal softening function ${ }^{\Theta(T)} \mathrm{Eq}$. (5) and (6) for the power law are defined as:

$$
\begin{aligned}
& \Theta(T)=c_{0}+c_{1} T+c_{2} T^{2}+c_{3} T^{3}+c_{4} T^{4}+c_{5} T^{5}, \\
& \text { if } T<T_{\text {cut }}
\end{aligned}
$$

$$
\Theta(T)=\Theta\left(T_{\text {cut }}\right)\left(1-\frac{T-T_{\text {cut }}}{T_{\text {melt }}-T_{\text {cut }}}\right) \text {, if } T \geq T_{\text {cut }}
$$

Where $c_{0}, c_{1}, c_{2}, c_{3}, c_{4}, c_{5}$ are coefficients for the polynomial fit, $\mathrm{T}$ is the temperature, $T_{\text {cut }}$ is the linear cut off temperature, and ${ }^{T_{\text {melt }}}$ the melting temperature. 


\subsection{Elastic stress model}

The elastic stress can be divided into mechanical stress and thermal stress. The simplified two dimensional mechanical-thermal model of the cutting process is shown in Fig. 1.

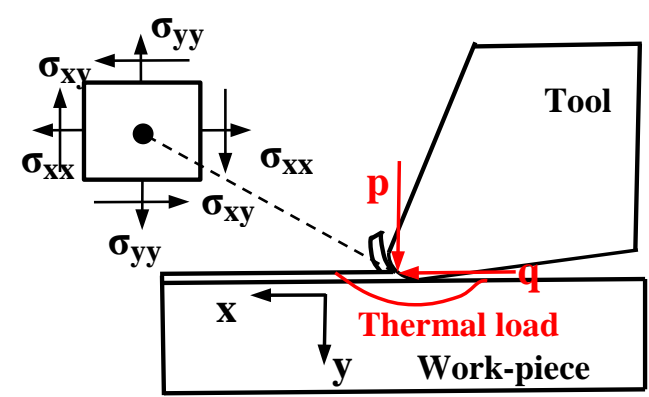

Fig.1. Two dimensional mechanical-thermal model of the cutting process

\subsubsection{Mechanical stress}

The stress generated by mechanical loading can be given by Eq. (7), (8) and (9) [23].

$$
\begin{aligned}
& \sigma_{x x}^{\text {mechanical }}=-\frac{2 y}{\pi} \int_{-a}^{a}\left(\frac{p(s)(x-s)^{2}+q(s)(x-s)^{3}}{\left((x-s)^{2}+y^{2}\right)^{2}}\right) d s \\
& \sigma_{y y}^{\text {mechanical }}=-\frac{2 y^{3}}{\pi} \int_{-a}^{a}\left(\frac{p(s)+q(s)(x-s)}{\left((x-s)^{2}+y^{2}\right)^{2}}\right) d s \\
& \sigma_{x y}^{\text {mechanical }}=-\frac{2 y^{2}}{\pi} \int_{-a}^{a}\left(\frac{p(s)(x-s)+q(s)(x-s)^{2}}{\left((x-s)^{2}+y^{2}\right)^{2}}\right) d s
\end{aligned}
$$

where normal force $\mathrm{p}(\mathrm{s})$, and tangential force $\mathrm{q}(\mathrm{s})$ can be given by Eq. (10) and (11) [23].

$$
\begin{aligned}
& p(s)=F_{y}\left(1-\frac{|s|}{a}\right) \\
& q(s)=F_{x}\left(1-\frac{|s|}{a}\right)
\end{aligned}
$$

Where $\mathrm{x}$ and $\mathrm{y}$ represent the distances from the contact point to the interest point. Where s represents the integration variable. Where fx and fy are the forces in cutting and feeding directions, respectively. Where a is the half contact length that can be given by Eq. (12) [23].

$$
a=\sqrt{\frac{4 P R}{\pi E_{R}}}
$$

Where $\mathrm{P}, \mathrm{R}$ and ER are the total normal force, the resultant radius of both the work-piece and the tool and the resultant elastic modulus respectively. These resultant values can be given by Eq. (13) [23].

$$
\frac{1}{R}=\frac{1}{R_{t}}+\frac{1}{R_{w}}, \frac{1}{E_{R}}=\frac{1}{E_{t}}+\frac{1}{E_{w}}
$$

where Rt, Rw and Et are the nose radius of the tool, the radius of the work-piece and the elastic modulus of the tool respectively.

\subsubsection{Thermal stress}

The thermal stress components are given by Eq. (14), (15), (16) and (17) [24].

$$
\begin{gathered}
\sigma_{x x}^{\text {thermal }}=-\frac{\alpha E}{1-2 \mu} \int_{0}^{\infty} \int_{-\infty}^{\infty}\left(G_{x h} \frac{\partial T}{\partial x}\left(x^{\prime}, y^{\prime}\right)+G_{x v} \frac{\partial T}{\partial y}\left(x^{\prime}, y^{\prime}\right)\right) \\
\cdot d x^{\prime} d y^{\prime}+\frac{2 y}{\pi} \int_{-\infty}^{\infty}\left(\frac{p(t)(t-x)^{2}}{\left((t-x)^{2}+y^{2}\right)^{2}}\right) d t-\frac{\alpha E T(x, y)}{1-2 \mu} \\
\sigma_{y y}^{\text {thermal }}=-\frac{\alpha E}{1-2 \mu} \int_{0}^{\infty} \int_{-\infty}^{\infty}\left(G_{y h} \frac{\partial T}{\partial x}\left(x^{\prime}, y^{\prime}\right)+G_{y v} \frac{\partial T}{\partial y}\left(x^{\prime}, y^{\prime}\right)\right) \\
\cdot d x^{\prime} d y^{\prime}+\frac{2 y^{3}}{\pi} \int_{-\infty}^{\infty}\left(\frac{p(t)}{\left((t-x)^{2}+y^{2}\right)^{2}}\right) d t-\frac{\alpha E T(x, y)}{1-2 \mu} \\
\sigma_{x y}^{\text {thermal }}=-\frac{\alpha E}{1-2 \mu} \int_{0}^{\infty} \int_{-\infty}^{\infty}\left(G_{x y h} \frac{\partial T}{\partial x}\left(x^{\prime}, y^{\prime}\right)+G_{x y v} \frac{\partial T}{\partial y}\left(x^{\prime}, y^{\prime}\right)\right) \\
\cdot d x^{\prime} d y^{\prime}+\frac{2 y^{2}}{\pi} \int_{-\infty}^{\infty}\left(\frac{p(t)(t-x)}{\left((t-x)^{2}+y^{2}\right)^{2}}\right) d t \\
p(t)=\frac{\alpha E T(x, y=0)}{1-2 \mu}
\end{gathered}
$$

Where $G_{x h}, G_{x v}, G_{y h}, G_{y v}, G_{x y h}$, and $G_{x y v}$ are the plane strain Green's functions.

\section{Simulation model and validation}

In this section, in order to verify the accuracy of simulation model, verification experiment and simulation were conducted with two schemes of machining parameters as shown in Table 2.

\subsection{Simulation model}

The milling process of ball end milling cutter and residual stress of work-piece can be simulated by the Third Wave AdvantEdge software as shown in Fig. 2.

\subsection{Comparison of residual stress between simulation and experiment}


As shown in Fig. 3(a), the $\mathrm{X}$ ray stress detector TEC4000 is employed to measure the residual stress in the $\mathrm{X}$ and $\mathrm{Y}$ directions on machined surfaces.

Fig. 3(b) shows that the residual stresses of simulation and experiment fit well. Because the errors of $\sigma x x$ and $\sigma y y$ are between $18 \mathrm{Mpa}$ and $31 \mathrm{Mpa}$, and the error ratios are between $13 \%$ and $17 \%$.

Table 2. Simulation and experiment schemes

\begin{tabular}{|c|c|c|c|c|c|}
\hline Scheme & $\begin{array}{c}\text { Tool } \\
\text { speed } \\
n \\
(r / \\
\text { min) }\end{array}$ & $\begin{array}{c}\text { Feed } \\
\text { per } \\
\text { tooth } \\
f_{z} \\
(\mathrm{~mm} / \\
\text { tooth) }\end{array}$ & $\begin{array}{l}\text { depth } \\
\text { of cut } \\
\text { ap } \\
(\mathrm{mm})\end{array}$ & $\begin{array}{l}\text { Cutting } \\
\text { width } \\
\text { ae } \\
(\mathrm{mm})\end{array}$ & $\begin{array}{c}\text { Tool } \\
\text { radius } \\
R \\
(\mathrm{~mm})\end{array}$ \\
\hline 1 & 8000 & 0.2 & 1 & 2 & 3 \\
\hline 2 & 12000 & 0.3 & 1.5 & 2 & 4 \\
\hline
\end{tabular}

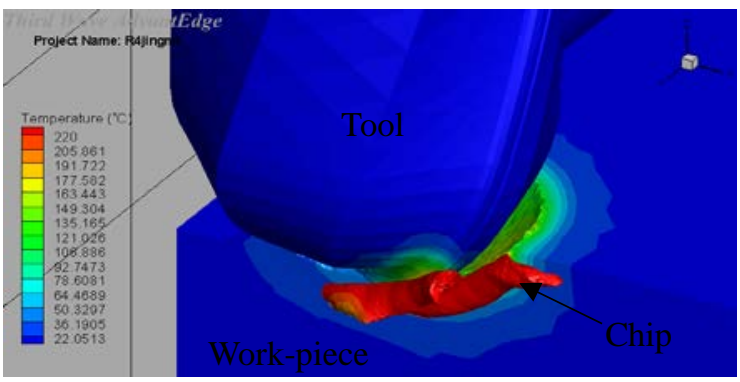

(a) Chip generation

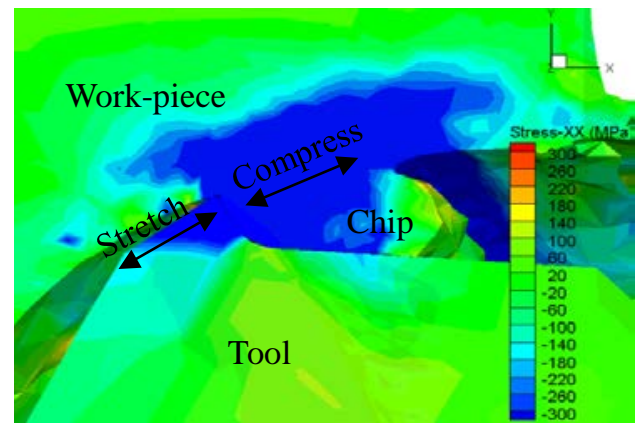

(b) Residual stress generation

Fig. 2. Simulation model

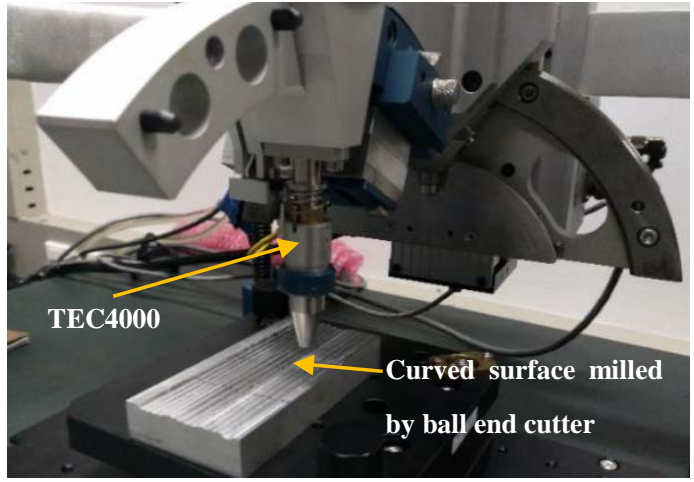

(a) Residual stress detection

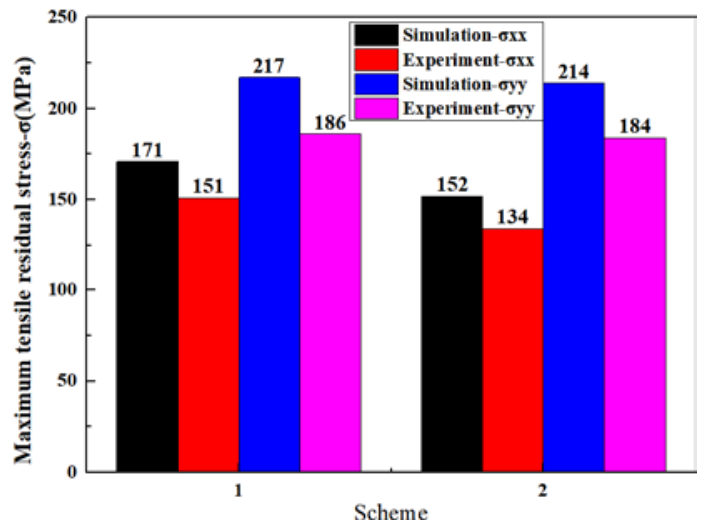

(b) Maximum residual stress on machined surface

Fig. 3. Residual stress detection and comparison of residual stress on machined surface

\section{Result and discussion}

\subsection{The effects of milling parameters on residual stress}

Section 4.1 mainly focus on the impacts of the milling parameters(milling speed, cutting depth, feeding speed and tool radius) on the maximum tensile residual stress of work-piece. The simulation parameters setting and results are shown in Fig. 4.

(1) The effect of milling speed on curved surface residual stress. It can be observed from Fig. 4(a) that with the increase of milling speed from 4000rpm to $16000 \mathrm{rpm}$, the maximum tensile residual stress in the $\mathrm{X}$, $\mathrm{Y}$ and $\mathrm{Z}$ direction can be reduced by $26.7 \%, 24.5 \%$ and $40.8 \%$.

(2) The effect of cutting depth on curved surface residual stress. Fig. 4(b) presents that with the enhancement of cutting depth from $0.5 \mathrm{~mm}$ to $2 \mathrm{~mm}$, the maximum tensile residual stress in the $\mathrm{X}, \mathrm{Y}$ and $\mathrm{Z}$ direction are increased by $19.8 \%, 40.6 \%$ and $23.3 \%$.

(3) The effect of feeding speed on curved surface residual stress. It can be observed from Fig. 4(c) that with the increase of feeding speed from $0.1 \mathrm{~mm} / \mathrm{z}$ to $0.4 \mathrm{~mm} / \mathrm{z}$, the maximum tensile residual stress in the $\mathrm{X}, \mathrm{Y}$ 
and $\mathrm{Z}$ direction are enhanced by $22.5 \%, 28.6 \%$ and $46.5 \%$.

(4) The effect of tool radius on curved surface residual stress. Fig. 4(d) demonstrates that with the enhancement of tool radius from $2.5 \mathrm{~mm}$ to $5 \mathrm{~mm}$, the maximum tensile residual stress in the $\mathrm{X}, \mathrm{Y}$ and $\mathrm{Z}$ direction can be declined by 24.2\%, 24.9\% and 27.3\%.

Therefore, the residual stress can be reduced by increasing milling speed and tool radius within a reasonable range. Conversely, the residual stress will be increased with the enhancement of cutting depth and feeding speed.

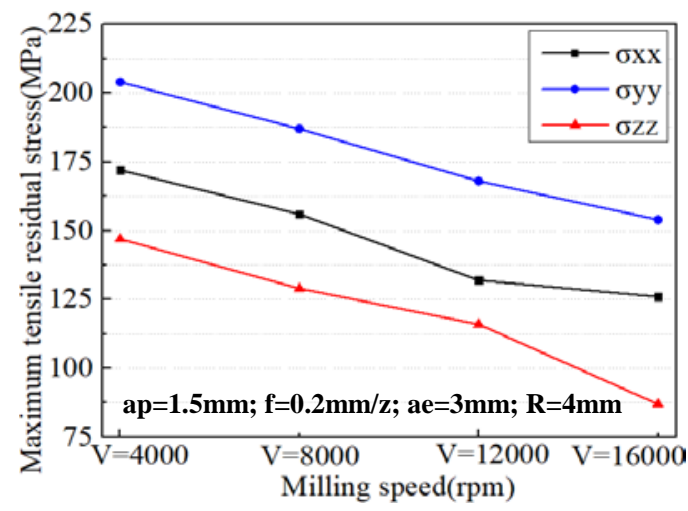

(a) The effects of milling speed on residual stress

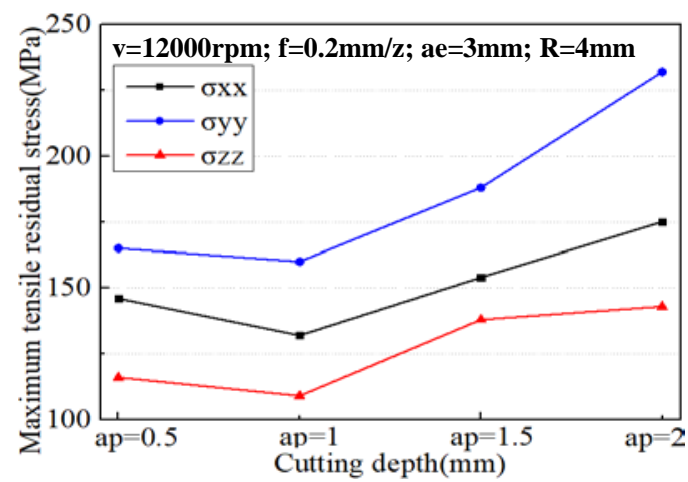

(b) The effects of cutting depth on residual stress

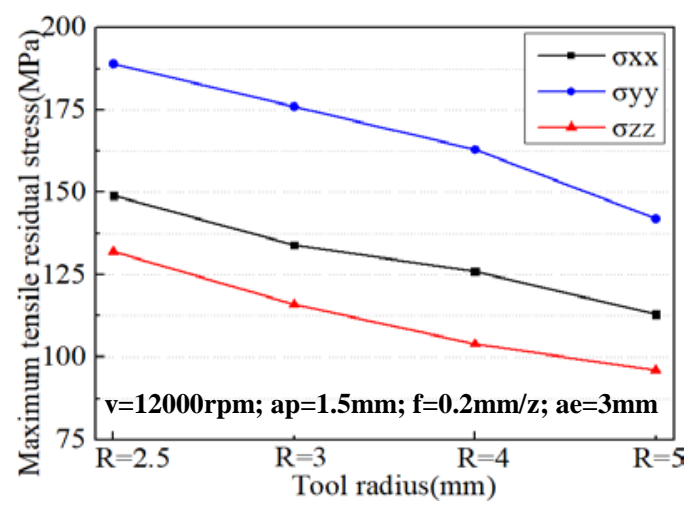

(c) The effects of feed per tooth on residual stress

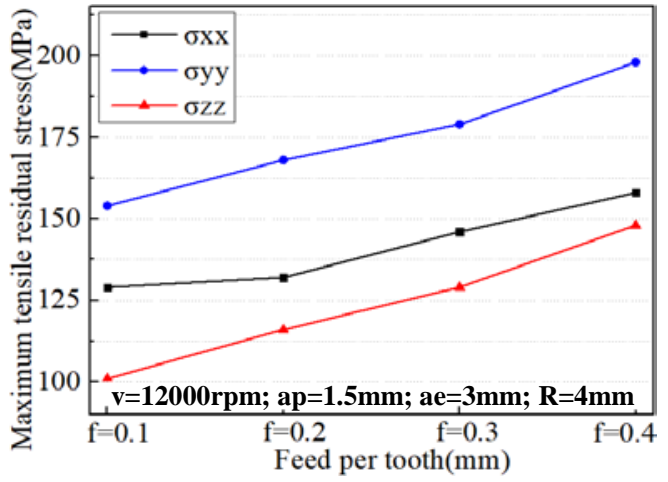

(d) The effects of tool radius on residual stress

Fig. 4. The effects of milling parameters on residual stress

\subsection{Superposition of curved surface residual stress}

In Section 4.2, four machining conditions are used to analyze the superposition of residual stress. The machining conditions are the first cutting of down milling, the second cutting of down milling, the first cutting of up milling and the second cutting of up milling respectively, as shown in Fig. 5(a), (b), (c) and (d). The four machining conditions have been performed with the simulation model in Section 3.1, and the machining parameters of Scheme 1 in Table 1 is used in the simulations of this section.

(1) The superposition of residual stress during down milling. It can be observed from Fig. 6(a) that the curved surface maximum tensile residual stress of down milling in the $\mathrm{X}, \mathrm{Y}$ and $\mathrm{Z}$ direction are increased by $27.4 \%, 40.4 \%$ and $21.8 \%$. In addition, Fig. 6(b) presents that the curved surface minimum tensile residual stress of down milling in the $\mathrm{X}, \mathrm{Y}$ and $\mathrm{Z}$ direction are enhanced by $38.6 \%, 47.3 \%$ and $32.8 \%$.

(2) The superposition of residual stress during up milling. It can be observed from Fig. 6(c) that the curved surface maximum tensile residual stress of up milling in the $\mathrm{X}, \mathrm{Y}$ and $\mathrm{Z}$ direction are increased by 38.7\%, 42.5\% and $32.9 \%$. Beside, Fig. 6(d) presents that the curved surface minimum tensile residual stress of up milling in the $\mathrm{X}, \mathrm{Y}$ and $\mathrm{Z}$ direction are enhanced by $37.8 \%$, 38.0\% and $28.0 \%$.

Therefore, under the processing conditions of this section, the following conclusions can be drown: (i) the curved surface residual stress induced by the subsequent cutting will be superimposed on the curved surface residual stress induced by the previous cutting; (ii) the superposition rates of residual stress induced by up milling are bigger than down milling. (iii) the curved surface maximum and minimum tensile residual stress of up milling are mostly larger than down milling. 


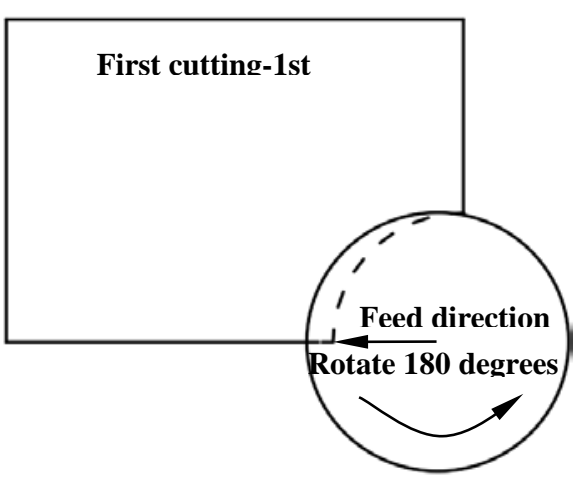

(a) First cutting of down milling

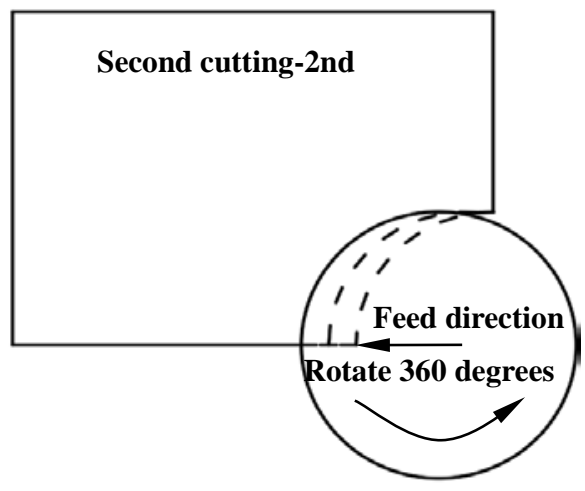

(b) Second cutting of down milling

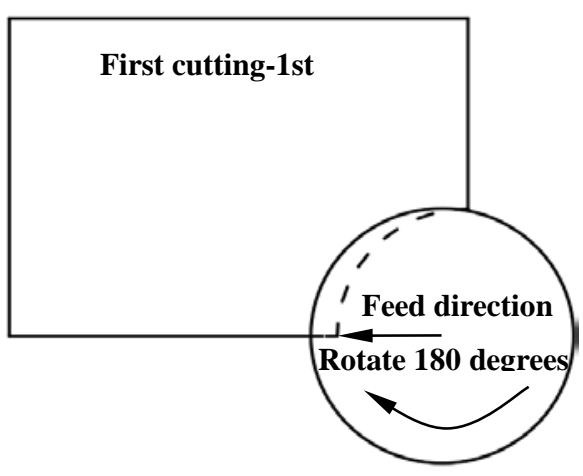

(c) First cutting of up milling

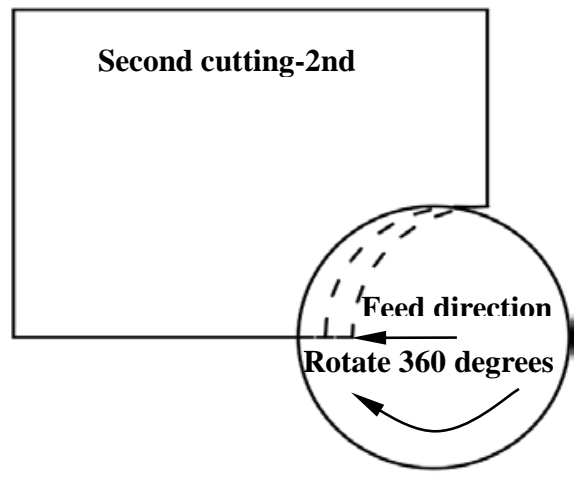

(d) Second cutting of up milling

Fig. 5. Machining conditions

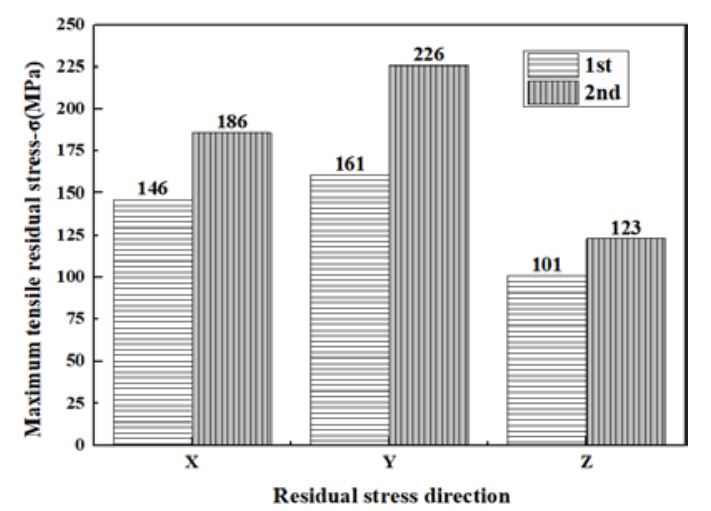

(a) Maximum residual stress of down milling

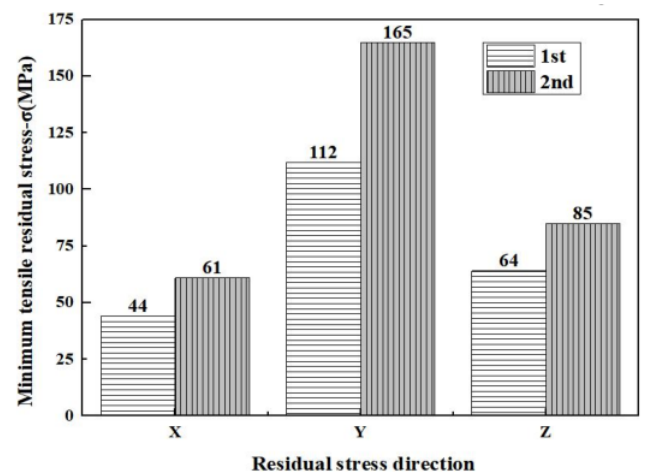

(b) Minimum residual stress of down milling

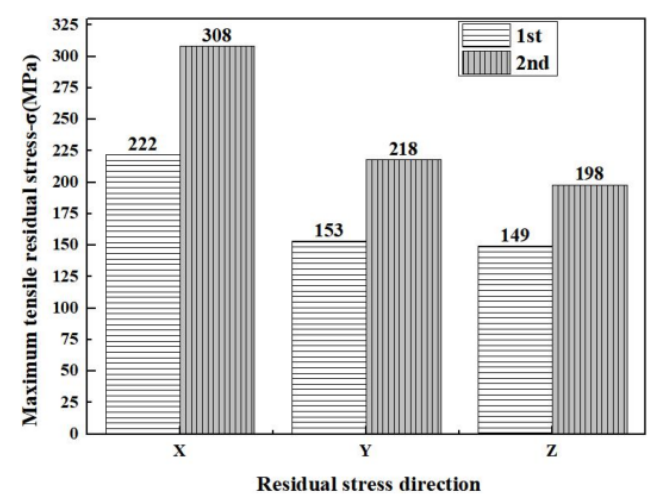

(c) Maximum residual stress of up milling

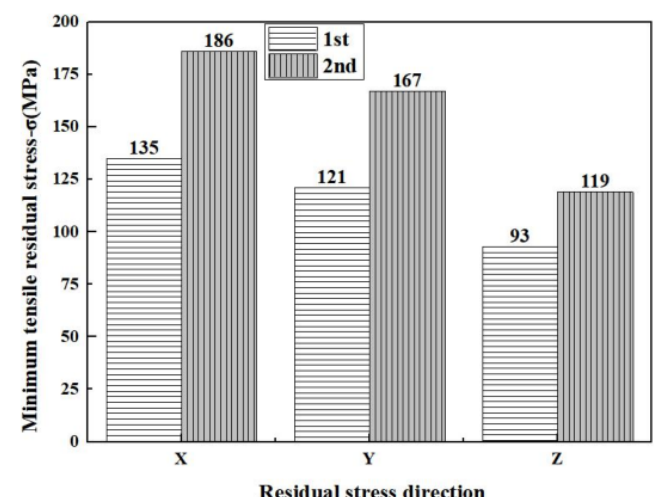

(d) Minimum residual stress of up milling

Fig.6. Curved surface residual stress superposition between first cutting and second cutting 


\section{Summary}

In this paper, a milling simulation model has been proposed and validated by comparing with the experimental data. Due to the application of the milling simulation model, important conclusions have been reached . First of all, it has been is found that by improving milling speed and tool radius within a reasonable range, the residual stress can be reduced, conversely, the residual stress increases with the encreasing cutting depth and feeding speed. Secondly, it has been pointed out that the curved surface residual stress induced by the subsequent cutting will be superimposed on the curved surface residual stress induced by the previous cutting. Thirdly, the superposition rates of residual stress induced by up milling are larger than down milling.

Acknowledge. This paper is supported by National Natural Science Foundation of China (Grant No. 51505291). We also thank the Center of Collective Use of MSUT "STANKIN" for providing resources.

\section{Reference}

1. N. Fan, M. Chen, P.Q. Guo, 2009 Chinese Control and Decision Conference, 5472-5475 (2009)

2. T. Segawa, H. Sasahara, M. Tsutsumi, International Journal of Machine Tools and Manufacture, 44(11) ,1215-1221 (2004)

3. M.N.A. Nasr, Procedia CIRP, 31,118-123 (2015)

4. X. Jiang, B. Li, J. Yang, X. Zuo, The International Journal of Advanced Manufacturing Technology, 68, 175-186 (2013)

5. K.-H. Fuh, C.-F. Wu, Journal of Materials Processing Technology 51(1-4), 87-105 (1995).

6. R.M. Arunachalam, M.A. Mannan, A.C. Spowage, International Journal of Machine Tools and Manufacture, 44(9), 879-887 (2004)

7. B. Li, X. Jiang, S.Y. Liang, Advanced Materials Research, 223, 456-463 (2011)

8. V. García Navas, O. Gonzalo, I. Bengoetxea, International Journal of Machine Tools and Manufacture, 61, 48-57 (2012)

9. B. Li, X. Jiang, J. Yang, S.Y. Liang, Journal of Materials Processing Technology, 216, 223-233 (2015)

10. J.S. Robinson, D.A. Tanner, C.E. Truman, R.C. Wimpory, Experimental Mechanics, 51(6), 981-993 (2010)

11. H.H. Zeng, R. Yan, F.Y. Peng, L. Zhou, B. Deng, The International Journal of Advanced Manufacturing Technology, 91(9-12), 3619-3634 (2017)

12. Y. Yang, L. Xia, G. Zhao, L. Meng, N. He, The International Journal of Advanced Manufacturing Technology, 98(1-4), 213-222 (2018)

13. Y.B. Guo, M.E. Barkey, International Journal of Mechanical Sciences, 46(3), 371-388 (2004)
14. M. Mohammadpour, M.R. Razfar, R. Jalili Saffar, Simulation Modelling Practice and Theory, 18(3), 378-389 (2010)

15. D. Yang, Z. Liu, X. Ren, P. Zhuang, International Journal of Mechanical Sciences, 108-109, 29-38 (2016)

16. B. Coto, V.G. Navas, O. Gonzalo, A. Aranzabe, C. Sanz, The International Journal of Advanced Manufacturing Technology, 53(9-12), 911-919 (2010)

17. S. Masoudi, S. Amini, E. Saeidi, H. Eslami-Chalander, The International Journal of Advanced Manufacturing Technology, 76(1-4), 597-608 (2014)

18. A. Singh, A. Agrawal, Journal of Materials Processing Technology, 225, 195-202 (2015)

19. D. Nespor, B. Denkena, T. Grove, V. Böß, Journal of Materials Processing Technology, 226, 15-24 (2015)

20. X. Jiang, X. Kong, Z. Zhang, Z. Wu, Z. Ding, M. Guo, International Journal of Mechanical Sciences, 167, 105162 (2020)

21. G.R. Johnson, W.H. Cook, Seventh Int. Symposium on Ballistics, P4.5, 541-547 (1983)

22. X. Jiang, B. Li, J. Yang, X. Zuo, K. Li, The International Journal of Advanced Manufacturing Technology, 66(9-12), 1439-1448 (2013)

23. I. Lazoglu, D. Ulutan, B.E. Alaca, S. Engin, B. Kaftanoglu, CIRP Annals, 57(1), 81-84 (2008)

24. D. Ulutan, B. Erdem Alaca, I. Lazoglu, Journal of Materials Processing Technology, 183(1), 77-87 (2007)

25. A. Isaev; V. Grechishnikov; P. Pivkin; Y. Ilyukhin; M. Kozochkin; P. Peretyagin, Epitoanyag-Journal Of Silicate Based And Composite Materials, 68(2), 46-51 (2016)

26. S.N. Grigoriev, V.A. Sinopalnikov, M.V. Tereshin, and V.D. Gurin, Measur. Techn., 55(5), 555-558 (2012)

27. S.N. Grigoriev, M.P. Kozochkin, F.S. Sabirov, and A.A. Kutin, Proc. CIRP, 1, 599-604 (2012) 